\title{
Esophageal Perforation in Children: Experience in Kurdistan Center for Gastroenterology and Hepatology/Iraq
}

\author{
Adnan M. H. Hamawandi', Aram Baram²*, Ali A. G. Ramadhan ${ }^{3}$, Taha A. Karboli4, \\ Abdulsalam Y. Taha², Ako Anwar ${ }^{5}$ \\ ${ }^{1}$ Department of Pediatrics, School of Medicine, Faculty of Medical Sciences, University of Sulaimani, Kurdistan \\ Center for Gastroenterology and Hepatology, Sulaymaniyah, Iraq \\ ${ }^{2}$ Department of Surgery, School of Medicine, Faculty of Medical Sciences, University of Sulaimani, Sulaimani \\ Teaching Hospital, Sulaymaniyah, Iraq \\ ${ }^{3}$ Department of Medicine, School of Medicine, Faculty of Medical Sciences, University of Duhok, Kurdistan \\ Center for Gastroenterology and Hepatology, Duhok, Iraq \\ ${ }^{4}$ Department of Medicine, School of Medicine, Faculty of Medical Sciences, University of Sulaimani, Kurdistan \\ Center for Gastroenterology and Hepatology, Sulaymaniyah, Iraq \\ ${ }^{5}$ Department of Anasthesia, Sulaimani Teaching Hospital, Kurdistan Center for Gastroenterology and \\ Hepatology, Sulaymaniyah, Iraq \\ Email: adnan_alhamwandi@yahoo.co.uk, aram.baramm@gmail.com, drrazooki@gmail.com, \\ alkarbolytaha2007@yahoo.com, salayt1963@hotmail.com, akoanwer@yahoo.com
}

Received 2 April 2014; revised 6 May 2014; accepted 14 May 2014

Copyright (C) 2014 by authors and Scientific Research Publishing Inc.

This work is licensed under the Creative Commons Attribution International License (CC BY).

http://creativecommons.org/licenses/by/4.0/

(c) (i) Open Access

\begin{abstract}
Background: Esophageal perforation is a rare, but potentially life threatening injury. The etiology and management of this condition have changed overtime. Iatrogenic causes are increasingly recognized and management is evolving towards more conservative approaches. Objective: To review our experience in the management of esophageal perforation in pediatric patients. Patients and methods: This retrospective study was conducted in the Kurdistan center for gastroenterology and hepatology in Sulaimani city. Review of records for cases of esophageal perforation during the period from January 2006 to October 2013 was performed. Results: Ten cases were found to have esophageal perforation. The causes of esophageal perforation were complications of endoscopic dilation for esophageal stricture $(n=7)$, button battery ingestion $(n=2)$, complication of esophagoscopy for corrosive injury $(n=1)$. The mean age was 42 months (range, 18 - 75 months). The diagnosis was made during the procedure in 6 cases, within 12 hours in 2 cases and late in the two cases of battery ingestion. Subcutaneous emphysema and respiratory distress were the main pre-
\end{abstract}

\footnotetext{
*Corresponding author.
} 
senting features. The location of perforation was thoracic in 9 cases and cervical in 1 case. Conservative management was successful in 7 patients and surgical closure was done in two patients. One death has been reported. Conclusion: Iatrogenic causes were the most common causes of esophageal perforation. Conservative management with interventions guided by clinical response can have a favorable outcome and may become the best initial treatment strategy in the future. Further larger scale studies are recommended to establish the best protocol for conservative management.

\section{Keywords}

Dilatation, Esophageal Perforation, Children, Conservative Management, Sulaimani

\section{Introduction}

Esophageal perforation (EP) is a rare, but it is a potentially life threatening injury that can quickly lead to the development of mediastinitis, sepsis, and possible multiorgan failure in the absence of prompt recognition and treatment [1]. Diverse non-traumatic causes have been reported in the etiology of EP in children including dilation, endoscopy, foreign bodies, corrosive injury, gastric tube insertion, endotracheal intubation and transesophageal echocardiography [2]-[4].

Surgical therapy has been the traditional and preferred method of treatment; however, less invasive approaches to EP continue to evolve [5] [6]. In the contemporary era, primary repair of esophageal perforations is becoming widely accepted as the treatment of choice, and several studies have demonstrated respectable mortality and morbidity rates with benign perforations, even with delayed presentation. Obviously, if the esophagus is devitalized or contains malignant disease, alternative methods of treatment other than primary repair should be undertaken [6]. As the incidence of EP increases with the advancement of invasive endoscopic procedures, early recognition of clinical features and implementation of effective treatment are essential for a favorable clinical outcome with minimal morbidity and mortality [7]. Several options exist for managing the various types of esophageal perforations has prompted several authors to review their experience with this challenging and potentially deadly entity [5]-[7]. Thus, the aim of this study was to review our experience in the management of EP and the outcome of such management in pediatric patients.

\section{Patients and Methods}

We reviewed retrospectively records of cases of esophageal perforations in children that were treated, during the period from January 2006 to October 2013, by the authors in the Kurdistan center for Gastroenterology and Hepatology (KCGH), Sulaimani, Iraq. The KCGH is the only tertiary center in Kurdistan serving about 4,000,000 population; with average annual 1000 pediatric patients. The reviewed records included 84 cases of endoscopic esophageal dilatation undergone 784 dilatation sessions, 426 cases of esophagogastroduodenoscopy and 40 cases of foreign body ingestion. Data collected included patient's age, etiology, signs and symptoms, radio-imaging, treatment modalities, hospital stay and outcome. Patients with postoperative anastomotic leaks with drains in place were excluded. Endoscopic examinations were done under general anesthesia with airway protection, using flexible Gastroscope (Olympus Exera GIF Q180). All patients were considered critically ill and admitted to intensive care unit, kept in state of nil per mouth and appropriate intravenous fluid with intravenous broad spectrum antibiotics initiated. Water soluble contrast esophagoraphy was done to localize the perforation and assess its size. The vital signs, oxygen saturation, neck and chest physical signs were monitored closely. All patients were followed by daily chest X-ray, particularly during the first few days. Eight patients were stable and conservative line of management was followed; while deterioration in physical findings, vital signs and radiological findings in 2 patients were the indication for surgical management.

\section{Results}

During the study period there were 10 cases with EP (Table 1); 5 boys and 5 girls with a mean age of 42 months (range, 18 - 75 months). Complication of Savary endoscopic dilation for esophageal stricture was the cause in 7 
Table 1. Demographic and clinical characteristic of patients $(\mathrm{N}=10)$.

\begin{tabular}{|c|c|c|c|c|c|c|c|}
\hline $\begin{array}{l}\text { Case } \\
\text { no. }\end{array}$ & $\begin{array}{l}\text { Age in } \\
\text { months }\end{array}$ & Gender & Cause of perforation & $\begin{array}{l}\text { Days to } \\
\text { Diagnosis }\end{array}$ & $\begin{array}{l}\text { Signs and } \\
\text { symptoms }\end{array}$ & Chest X-ray & $\begin{array}{l}\text { Location of the } \\
\text { perforation }\end{array}$ \\
\hline 1 & 72 & Male & $\begin{array}{l}\text { Savary dilation for corrosive stricture } \\
\text { under fluoroscopic guidance }\end{array}$ & 0 & $\begin{array}{l}\text { Subcutaneous } \\
\text { emphysema }\end{array}$ & $\begin{array}{l}\text { Subcutaneous } \\
\text { emphysema }\end{array}$ & Cervical \\
\hline 2 & 32 & Female & $\begin{array}{l}\text { Savary dilation for corrosive stricture } \\
\text { under fluoroscopic guidance }\end{array}$ & 1 & $\begin{array}{l}\text { Respiratory } \\
\text { distress }\end{array}$ & $\begin{array}{l}\text { Right Pneumothorax and } \\
\text { Pneumomediastinum }\end{array}$ & Thoracic \\
\hline 3 & 45 & Male & $\begin{array}{l}\text { Savary dilation for corrosive stricture } \\
\text { under fluoroscopic guidance }\end{array}$ & 1 & $\begin{array}{l}\text { Respiratory } \\
\text { distress }\end{array}$ & Pneumomediastinum & Thoracic \\
\hline 4 & 36 & Female & Endoscopy for corrosive ingestion & 0 & Respiratory distress & Pneumomediastinum & Thoracic \\
\hline 5 & 75 & Female & $\begin{array}{l}\text { Savary dilation for corrosive stricture } \\
\text { under fluoroscopic guidance }\end{array}$ & 0 & Respiratory distress & Pneumomediastinum & Thoracic \\
\hline 6 & 30 & Female & Ingestion of button battery & 7 & Respiratory distress & $\begin{array}{l}\text { Button battery in the } \\
\text { esophagus }\end{array}$ & Thoracic \\
\hline 7 & 28 & Male & Ingestion of button battery & 5 & Respiratory distress & $\begin{array}{l}\text { Button battery in the } \\
\text { esophagus }\end{array}$ & Thoracic \\
\hline 8 & 22 & Male & Balloon dilation for peptic stricture & 0 & $\begin{array}{l}\text { Respiratory distress } \\
\text { and emphysema }\end{array}$ & $\begin{array}{l}\text { Right Pneumothorax and } \\
\text { Pneumomediastinum }\end{array}$ & Thoracic \\
\hline 9 & 62 & Male & $\begin{array}{l}\text { Savary dilation for corrosive stricture } \\
\text { under fluoroscopic guidance }\end{array}$ & 0 & $\begin{array}{l}\text { Respiratory distress } \\
\text { and emphysema }\end{array}$ & $\begin{array}{l}\text { Right Pneumothorax and } \\
\text { Pneumomediastinum }\end{array}$ & Thoracic \\
\hline 10 & 18 & Female & $\begin{array}{l}\text { Balloon dilation for } \\
\text { congenital stricture }\end{array}$ & 0 & $\begin{array}{l}\text { Respiratory distress } \\
\text { and emphysema }\end{array}$ & Subcutaneous emphysema & Thoracic \\
\hline
\end{tabular}

cases (corrosive 5, peptic 1 and congenital 1). Two cases were due to button alkaline battery ingestion and 1 case was a complication of endoscopy (video scope) for corrosive injury. The diagnosis was made during the procedure in 6 cases, within 12 hours in 2 cases and late (5 and 7 days) in 2 cases of battery ingestion. Subcutaneous emphysema and respiratory distress were the main presenting features. Chest X-ray showed pneumomediastinum with or without pneumothorax in 7 cases, subcutaneous emphysema in 1 case and button battery in 2 cases. The location of perforation was thoracic in 9 cases and cervical in 1 case. During the period of the study 7 cases treated successfully by conservative method, one family refused surgery and the baby died by sepsis, 2 patients needed surgery. Only one patient had troublesome Dysphagia which required dilatation.

\section{Management of the Cases}

All cases were admitted to intensive care unit. They were on intravenous fluid and nothing per month for 5 - 21 days and on broad spectrum antibiotics covering aerobic and anaerobic bacteria for 7 - 28 days (Table 2). The length of hospital stay was 7 - 36 days. Five patients needed tube thoracostomy for drainage of pleural effusion, two patients required gastrostomy tube feeding and surgical operation to close the perforation, left side posterolateral incision performed in both patients, intraoperatively a large perforation in the lower third of the esophagus was found with severe contamination of the pleural cavity and early signs of mediastinitis. The site of perforation composed of friable tissue and primary repair failed necessitatinga pleural flap for closure of the perforation. Non-operative management succeeded in 7 cases, esophageal stenting was tried in 1 case but the stent migrated to the stomach after 24 hours. Contrast (water soluble) esophagography was done on $5^{\text {th }}-21^{\text {st }}$ day according to the degree of the leak and response to conservative management. One case of button battery ingestion died on $7^{\text {th }}$ day at home (the family discharged him from hospital on first day as they refused surgery), 8 cases had adequate oral intake and one case still having dysphagia and is on regular endoscopic dilation.

\section{Discussion}

Despite medical developments, EP continues to carry a significant mortality and morbidity especially with de- 
Table 2. Managementof patients $(\mathrm{N}=10)$.

\begin{tabular}{ccccccccccc}
\hline $\begin{array}{c}\text { Case } \\
\text { No. }\end{array}$ & $\begin{array}{c}\text { Chest tube } \\
\text { drainage }\end{array}$ & $\begin{array}{c}\text { Gastrostomy } \\
\text { tube feeding }\end{array}$ & $\begin{array}{c}\text { Esophageal } \\
\text { stenting }\end{array}$ & $\begin{array}{c}\text { Surgical or } \\
\text { Conservative }\end{array}$ & $\begin{array}{c}\text { Antibiotics } \\
\text { duration (days) }\end{array}$ & $\begin{array}{c}\text { Date of contrast } \\
\text { Esophagogram }\end{array}$ & $\begin{array}{c}\text { NPO } \\
\text { days }\end{array}$ & $\begin{array}{c}\text { Hospital } \\
\text { stay (days) }\end{array}$ & Outcome \\
\hline 1 & None & None & None & Conservative & 7 & $5^{\text {th }}$ & 5 & 7 & Adequate PO \\
2 & Done & None & None & Conservative & 10 & $7^{\text {th }}$ & 7 & 10 & Adequate PO \\
3 & Done & None & None & Conservative & 14 & $7^{\text {th }}$ & 7 & 14 & Dysphagia \\
4 & None & None & None & Conservative & 7 & $5^{\text {th }}$ & 5 & 7 & Adequate PO \\
5 & None & None & None & Conservative & 7 & $5^{\text {th }}$ & 5 & 7 & Adequate PO \\
6 & Done & Done & None & Surgical closure & 28 & $21^{\text {st }}$ & 21 & 36 & Adequate PO \\
7 & NA & None & None & Refused surgery & N/A & NA $^{2}$ & NA & NA & Died \\
8 & Done & Done & Done (Migrated) & Surgical closure & 14 & $14^{\text {th }}$ & 14 & 18 & Adequate PO \\
9 & Done & None & None & Conservative & 7 & $5^{\text {th }}$ & 5 & 7 & Adequate PO \\
10 & None & None & None & Conservative & 7 & $5^{\text {th }}$ & 5 & 5 & Adequate PO \\
\hline
\end{tabular}

PO: Per Os.

layed recognition and treatment [8] [9]. The clinical manifestations of early EP can be vague and nonspecific. Therefore, a high index of suspicion is the safeguard against delayed diagnosis [7].

There have been two major shifts in our knowledge about EP. The first shift relates to the etiology of EP which has changed overtime. The etiology of esophageal injuries has changed over time. While spontaneous injury was the most common cause in the past $60 \%$, today, iatrogenic injury $75 \%$ has replaced it due to the widespread use of endoscopic applications for diagnostic and treatment purposes [9]. The second shift concerns the treatment of EP. Although the operative management was the most common treatment modality, the current approach to EP treatment in children has shifted towards conservative management [1]. This is especially important in resource limited areas where there is very small number of thoracic pediatric surgeons in addition to the lack facilities [10].

In this study, the most common cause of EP was iatrogenic in the form of esophageal instrumentation for diagnostic and therapeutic purposes (80\%). This is consistent with other studies in the pediatric age group reporting $71 \%$ - 84\% of EP as being iatrogenic in etiology [1] [2] [11] [12]. Dilation of corrosive esophageal strictures contributed to $50 \%$ of the cases of EP in this study. These strictures are usually long $(>10 \mathrm{~cm})$, eccentric and tight, thus technically more difficult to dilate and more likely associated with EP during endoscopic dilation. This finding correlates with those from studies done in Iraq, Pakistan and India where corrosive strictures are more commonly encountered than in the West [13] [14]. Two cases (20\%) were due to ingestion of button batteries which are currently among the common foreign bodies ingested accidentally by the children as they are now included in many small toys and electronic devices that are accessible to young children [15].

The most common clinical manifestations in this study were respiratory distress and subcutaneous emphysema. The clinical presentation of EP depends on the etiology, location of the injury, size of the perforation, degree of contamination, time elapsed after injury, and presence of associated injury [7]. The most common symptoms are pain, fever, dysphagia, and dyspnea [9]. In this study, subcutaneous emphysema was detected in 3 out of 9 cases (33\%) with thoracic EP. Subcutaneous emphysema can be detected in 30\% of patients with thoracic EP and in $60 \%$ of patients with cervical EP [7].

Diagnosis of an EP relies on radiographic evidence [17]. In this study, the chest X-ray revealed indirect evidence of perforation as (pneumomediastinum, pneumothorax and/or subcutaneous emphysema) in $80 \%$ of cases. The chest X-ray may be used as the initial diagnostic test; however, plain films may be normal in $12 \%$ to $33 \%$ of cases and they cannot identify the location of perforation in addition to the difficulty in determining the degree of containment which is more easily judged using contrast studies and CT scan of chest and upper abdomen [16]. The most common site of perforation was in the thoracic esophagus with cervical EP reported in only one case. This is comparable to the findings of a study conducted by Carey et al. [1].

The most important factor determining morbidity and mortality in EP is early diagnosis and determination of 
the treatment method that best suits the patient. The reported mortality rates in the literature are $0 \%-18 \%$ in early diagnosis and $7 \%-37.5 \%$ in late diagnosis [9]. In this study, all the patients who underwent dilation for esophageal strictures had a post-dilation "check" upper endoscopy with the aim of reconfirming the site and length of stricture, assessing adequacy of dilation, looking for abnormalities in the stomach and duodenum in addition to any evidence of perforation. This post-dilation upper endoscopy combined with water soluble contrast study in suspected cases was helpful in making the diagnosis during the procedure in 5 patients who underwent dilation for esophageal stricture. Although the role of upper endoscopy in the early diagnosis of suspected EP is debatable [16], as it may worsen the injury and is less accurate than contrast studies [1], in patients with high suspicion of perforation and negative radiography, or when swallowing a contrast agent is impossible for technical reasons, flexible endoscopy should be considered [17]. The late diagnosis in the two cases of button batteries ingestion may be attributed to the un-witnessed ingestion of button batteries and that early clinical manifestations are non-specific in addition to the fact that up to $35 \%$ of the pediatric population may be asymptomatic after gastrointestinal foreign body ingestion [18]. The only child who died in this study was diagnosed late and discharged on the same day by the family members who refused surgery.

Management of EP in the pediatric age group has historically been based on adult schemes which favored operative intervention in the belief that this has reduced morbidity and mortality compared to conservative management but pediatricians realize that children have different causes and a greater propensity to heal, and consequently require different management [1]. Although the consensus of what constitutes conservative management is unclear, many centers utilize an initial conservative management with the operative intervention guided by the patient's clinical course [1]. Conservative management comprises minimizing proximal flow with nothing by mouth, controlling contamination with broad spectrum antibiotics and drainage and optimizing the overall clinical and nutritional status of the patient [1] [9].

In this study, there was clinical response to conservative management in 7 patients (70\%) with only two patients referred for surgical closure after lack of improvement on conservative management. This high rate of success with conservative management has been shown in other studies and reports [1] [11] [12] [19].

The conservative management included nothing per mouth with intravenous fluid for $5-7$ days. This period of nothing by mouth was generally shorter than that reported in other studies [1] [19]. Also it was shorter than the period of nothing per os (NPO) in those treated with surgical closure (14 - 21 days), in whom, the nutritional support was provided through the gastrostomy tube which was inserted at the time of surgery for esophageal perforation as the gastrostomy tube insertion needs general anesthesia. Feeding using naso-enteral tubes or total parenteral nutrition was avoided in this study to prevent the complications associated with both of these modalities of nutrition although they have been used more extensively in other studies [1] [19].

Infectious complications was controlled using antibiotics covering aerobic and anaerobic bacteria in addition to intercostal chest tube drainage which was needed in 3 of the 7 patients who underwent conservative management compared to both of the patients who underwent surgical intervention. The duration of antibiotic use was guided by the clinical response and was comparable to that in the Carey et al. study [1] for patients treated conservatively. Although the use of intercostal chest tube drainage has been advocated as a part of aggressive conservative management protocol [11], other studies have shown that delaying such intervention may be reasonable in patients who are clinically improving [1]. We used intercostal chest tube drainage for patients who had detectable pleural effusion on initial or follow up clinical examination or radiography.

Although 6 of our patients were diagnosed with esophageal perforation during the procedure, esophageal stenting was tried in only one of them using a covered self-expandable metallic stent. Unfortunately this stent migrated to the stomach after 24 hours. The use of self-expandable metallic stents for esophageal perforation is an increasingly used modality in the hope that it may shorten the hospitalization period, reduce the cost of management, and allow for early resumption of oral nutrition [9] [20] [21]. However, complications such as stent migration have been reported in 5\% - 23\% [9] and this complication occurred in the only case in which a selfexpandable metallic stent was deployed.

We followed our patients with water soluble contrast esophagography on the $5^{\text {th }}$ to $7^{\text {th }}$ day in the conservative management group (average 5.6 days) and on the $14^{\text {th }}$ to $21^{\text {st }}$ day in the group treated with surgical closure. The timing of contrast study was judged by the overall clinical response to treatment. In the group treated conservatively, the timing of contrast study was less than that reported in other studies (average 10 days) [9] [19]. Patients treated with conservative management had shorter hospital stay (average, 8.1 days) compared to those treated with surgical closure (18 - 36 days). In this study, the hospital stay for patients treated conservatively was 
less than that reported in other studies [1] [19].

The long-term outcome of esophageal perforation depends on the underlying condition and is good in those with a normal esophagus prior to perforation [2]. The majority of children requiring further interventions following conservative management had a preexisting stenosis [1]. In this study, the overall clinical outcome in both the conservative and surgical groups was adequate oral intake in 8 patients with only one patient having dysphagia and is on regular endoscopic dilation. The persistent need for intervention in this patient may indicate the severity of his underlying corrosive stricture rather than failure of conservative management or a long-term sequel of esophageal perforation.

\section{Conclusion}

In conclusion, iatrogenic complications were the most common causes of esophageal perforation. Conservative management with interventions guided by clinical response can have a favorable outcome and may become the best initial treatment strategy in the future. Further larger scale studies are recommended to establish the best protocol for conservative management.

\section{Limitations of Our Study}

One of the limitations of the current study was the small, non-probability sample of convenience. The size, convenience, and homogeneity of the sample limit the generalizability of the results of our study. Thus, the power analysis was rerun to direct future researches with the primary focus to be changed to the outcome of the either conservative or operative methods.

Another limitation was that the measurements and intervention were made without blinding the researcher to the experimental group, which has the potential for bias. However, potential bias was minimized by random assignment of participants and the following of standardized protocol by the investigator.

A short post-operative follow-up period is a limitation for a number of reasons. Longer follow-up at 6 and 12 weeks following surgery or the conservative cases would confirm the results or uncover more or less favorable results over time.

\section{Author Contributions}

Study conception and design: Adnan M. H. Hamawandi; Acquisition of data, manuscript preparation: Aram Bram, Ali A. G. Ramadhan; Analysis and interpretation of data: Adnan M. H. Hamawandi, Aram Baram; Drafting of manuscript: Aram Baram, Abdulsalam Y. Taha, Taha A. Karboli, Ako Anwar.

\section{Acknowledgements}

We are grateful to all the patients and clinical staff.

\section{Conflict of Interest Statement}

None of the authors has any potential conflict of interest.

\section{References}

[1] Garey, C.L., Laituri, C.A., Kaye, A.J., Ostlie, D.J., Snyder, C.L., Holcomb III, G.W., et al. (2010) Esophageal Perforation in Children: A Review of One Institution's Experience. Journal of Surgical Research, 164, 13-17. http://dx.doi.org/10.1016/j.jss.2010.05.049

[2] Gander, J.W., Berdon, W.E. and Cowles, R.A. (2009) Iatrogenic Esophageal Perforation in Children. Pediatric Surgery International, 25, 395-401. http://dx.doi.org/10.1007/s00383-009-2362-6

[3] Panieri, E., Millar, A.J.W., Rode, H., Brown, R.A. and Cywes, S. (1996) Iatrogenic Esophageal Perforation in Children: Patterns of Injury, Presentation, Management, and Outcome. Journal of Pediatric Surgery, 31, 890-895. http://dx.doi.org/10.1016/S0022-3468(96)90404-2

[4] Sasaki, T., Culham, G. and Gandhi, S.K. (2012) Conservative Management of Iatrogenic Esophageal Perforation during Neonatal Cardiac Surgery. World Journal for Pediatric and Congenital Heart Surgery, 3, 528-530. http://dx.doi.org/10.1177/2150135112443268 
[5] Ryom, P., Ravn, J.B., Penninga, L., Schmidt, S., Iversen, M.G., Skov-Olsen, P., et al. (2011) Aetiology, Treatment and Mortality after Oesophageal Perforation in Denmark. Danish Medical Bulletin, 58, A4267.

[6] Bhatia, P., Fortin, D., Inculet, R.I. and Malthaner, R.A. (2011) Current Concepts in the Management of Esophageal Perforations: A Twenty-Seven Year Canadian Experience. The Annals of Thoracic Surgery, 92, 209-215. http://dx.doi.org/10.1016/j.athoracsur.2011.03.131

[7] Wu, J.T., Mattox, K.L. and Wall Jr., M.J. (2007) Esophageal Perforations: New Perspectives and Treatment Paradigms. The Journal of Trauma-Injury, Infection and Critical Care, 63, 1173-1184. http://dx.doi.org/10.1097/TA.0b013e31805c0dd4

[8] Lin, M.T., Tai, W.C., Chiu, K.W., Chou, Y.P., Tsai, M.C., Hu, T.H., et al. (2009) Delayed Presentation of Intrathoracic Esophageal Perforation after Dilation for Achalasia. World Journal of Gastroenterology, 15, 4461-4463. http://dx.doi.org/10.3748/wjg.15.4461

[9] Şengül, A.T., Büyükkarabacak, Y.B., Yetim, T.D., Pirzirenli, M.G., Çelik, B. and Başoğlu, A. (2013) Early Diagnosis Saves Lives in Esophageal Perforations. Turkish Journal of Medical Sciences, 43, 1-7.

[10] Balumuka, D.D., Chalya, P.L. and Mahalu, W. (2011) Oesophageal Perforation: A diagnostic and Therapeutic Challenge in a Resource Limited Setting: A Report of Three Cases. Journal of Cardiothoracic Surgery, 6, 116. http://dx.doi.org/10.1186/1749-8090-6-116

[11] Martinez, L., Rivas, S., Hernandez, F., Avila, L.F., Lassaletta, L., Murcia, J., et al. (2003) Aggressive Conservative Treatment of Esophageal Perforations in Children. Journal of Pediatric Surgery, 38, 685-689. http://dx.doi.org/10.1016/jpsu.2003.50183

[12] Li, P., Xu, Q., Ji, Z.Z., Gao, Y., Zhang, X.S., Duan, Y.T., et al. (2006) Video-Thoracoscopic Drainage for Esophageal Perforation with Mediastinitis in Children. Journal of Pediatric Surgery, 41, 514-517. http://dx.doi.org/10.1016/j.jpedsurg.2005.11.047

[13] Qureshi, S., Ghazanfar, S., Leghari, A., Tariq, F., Niaz, S.K. and Quraishy, M.S. (2008) Benign Esophageal Strictures: Behaviour, Pattern and Response to Dilatation. The Journal of the Pakistan Medical Association, 60, 656-660.

[14] Hamawandi, A.M., Karboli, T.A., Abdullah, A.A. and Ali, A.J. (2010) Endoscopic Dilatation of Esophageal Strictures in Children: Causes and Outcome in 47 Cases. Duhok Medical Journal, 4, 30-38.

[15] Centers for Disease Control and Prevention (2012) Injuries from Batteries among Children Aged $<13$ Years—United States, 1995-2010. Morbidity and Mortality Weekly Report, 61, 661-666.

[16] Arantes, V., Campolina, C., Valerio, S.H., de Sa, R.N., Toledo, C., Ferrari, T.A., et al. (2009) Flexible Esophagoscopy as a Diagnostic Tool for Traumatic Esophageal Injuries. The Journal of Trauma-Injury, Infection and Critical Care, 66, 1677-1682. http://dx.doi.org/10.1097/TA.0b013e31818c1564

[17] Søreide, J.A. and Viste, A. (2011) Esophageal Perforation: Diagnostic Work-Up and Clinical Decision-Making in the First 24 Hours. Scandinavian Journal of Trauma, Resuscitation and Emergency Medicine, 19, 1-7.

[18] Eren, S., Alper, A., Nasır, A. and Gürkan, F. (2007) Esophageal Button Battery Ingestion: A Delayed Diagnosis. Turkish Respiratory Journal, 8, 32-33.

[19] Rayes, O.M. (2013) Conservative Management of Instrumental Esophageal Perforation in Children: A Review of One surgeon's Experience. Life Science Journal, 10, 1941-1914.

[20] Hunerbein, M., Stroszczynski, C., Moesta, K.T. and Schlag, P.M. (2004) Treatment of Thoracic Anastomotic Leaks after Esophagectomy with Self-Expanding Plastic Stents. Annals of Surgery, 240, 801-807. http://dx.doi.org/10.1097/01.sla.0000143122.76666.ae

[21] Johnsson, E., Lundell, L. and Liedman, B. (2005) Sealing of Esophageal Perforation or Ruptures with Expandable Metallic Stents: A Prospective Controlled Study on Treatment Efficacy and Limitations. Diseases of the Esophagus, 18, 262-266. http://dx.doi.org/10.1111/j.1442-2050.2005.00476.x 